Western University Scholarship@Western

1981

\title{
Long-Run Industry Equilibrium with Uncertainty
}

Elie Appelbaum

Chin Lim

Follow this and additional works at: https://ir.lib.uwo.ca/economicsresrpt

Part of the Economics Commons

Citation of this paper:

Appelbaum, Elie, Chin Lim. "Long-Run Industry Equilibrium with Uncertainty." Department of Economics Research Reports, 8107. London, ON: Department of Economics, University of Western Ontario (1981). 
ISBN: $\quad 0-7714-0269-4$

\author{
RESEARCH REPORT 8107 \\ LONG-RUN INDUSTRY EQUILIBRIUM WITH \\ UNCERTAINTY \\ by \\ Elie Appelbaum \\ and \\ Chin Lim
}

May, 1981 
I. INTRODUCTION

While the theory of the firm under uncertainty is quite extensive and developed, ${ }^{1}$ there are only few studies that went on to consider the effects of uncertainty on the structure of industry equilibrium. For those studies that do focus on this issue (see Dreze and Gabszewicz (1967), Sheshinski and Dreze (1976), and Lippman and McCall (1981)), the more important results that were obtained can be summarized as follows: In an environment of demand uncertainty, (a) risk-neutral firms in competitive equilibrium operate with excess capacity (i.e., output is below the level that minimizes average costs), and (b) increasing demand uncertainty increases the equilibrium number of risk-neutral firms in the industry.

At first glance, result (b) seems to be surprising. According to intuition, increasing uncertainty should increase the risk of operating a firm and, hence, should make it less attractive for firms to enter the industry. Result (b), however, implies just the opposite. It suggests that incentives for entry increase with demand uncertainty. It must therefore follow that existing firms' expected profits must be increasing with increasing price uncertainty in order to provide the incentives for entry. It turns out that this result is an immediate corollary of $0 i^{\prime} s$ (1961) theorem: If a firm with increasing marginal cost equates ex post price to marginal cost, then the profit function is a strictly increasing convex function of price, and as a consequence, a mean-preserving increase in price uncertainty will raise expected profits.

The novelty of this result, however, quickly fades once we take a closer look at the underlying behavioral assumptions that were used. In particular, to endow firms with the ability to equate ex post price to marginal cost is by no means an innocuous assumption. It suggests that a firm who is unsure of the 
market price next period need not commit itself to any production decision this period; it simply awaits the revelation of the price next period whence it instantaneously produces at a price equal to marginal cost. With such a complete ex post.flexibility, it is not surprising that price instability does not incur a 'risk' by the conventional usage of the word; on the contrary, it is a desired effect. Unfortunately, few industries have production processes that would allow them this luxury of complete ex post flexibility. Perhaps some service industries may be adequately represented by such a behavioral rule. For a large class of industries, however, complete ex post flexibility remains an unattainable luxury.

In general, complete ex post flexibility is not a 'free' good. Most production processes take time and firms usually commit themselves to some production decision ex ante because the ex ante cost function (for producing goods at a lower speed) they face is differentially lower than the ex post cost function (for producing goods at a higher speed) they will face if they await to produce after the revelation of the market price (see Turnovsky (1973)). This difference in costs represents the 'price' of ex post flexibility. In general, the optimal degree of ex post flexibility (i.e., the optimal mixture of ex ante and ex post production) that a firm will undertake is an endogenous variable --depending largely on the 'price' of ex post flexibility. The implications of this general behavior on the stochastic market equilibrium structure is explored in our forthcoming paper. ${ }^{2}$

In this paper, we consider the extreme case in which the 'price' of ex post flexibility is exceedingly high so that only ex ante production is pursued before the market price is revealed. In contrast to the opposite extreme of complete ex post flexibility, this extreme case bears more 
resemblance to the real world examples and especially those where production involves a long time lag. In fact, almost all agricultural commodities, to which the competitive paradigm seems most pertinent, are produced in this manner .

The effects of demand uncertainty on the Iong-run industry equilibrium structure obviously differ under the two polar behavioral modes. The rest of this paper will provide the contrasting predictions of the two models regarding the question of excess capacity and the effects of increasing uncertainty on the number and size of firms. This exercise is conducted not only for riskneutral firms but also risk-averse firms as well. In so doing, it indeed fills an important gap that currently exists in the literature.

II. THE MODEL

Consider a competitive industry of $N$ identical firms in which each firm $i(i=1, \ldots, N)$ produces a homogeneous commodity at output level $q_{i}$. The industry demand curve is stochastic and is given by

$$
p=p(q, \epsilon), \text { with } \frac{\partial p}{\partial q}<0 \text { and } \frac{\partial p}{\partial \epsilon}>0
$$

where $p$ is price; $\epsilon$ is a random variable with probability density $\mathrm{d} \Psi(\epsilon)$; and

$$
q=\sum_{i=1}^{N} q_{i}=N q_{i}
$$

is the aggregate industry output. Each firm is assumed to be managed by a manager ${ }^{3}$ who is assumed to maximize expected utility of profit $E[U(\pi)]$. The firm is assumed to choose output $q_{i}$ before price $p$ is revealed so that the profit ${ }^{4}$ $\pi\left(\mathrm{q}_{i}\right) \equiv \mathrm{pq}_{i}-\mathrm{c}\left(\mathrm{q}_{i}\right)$ (where $\mathrm{c}(\cdot)$ is the cost function) is a random variable. All managers are assumed to have an identical utility function $U(\cdot)$ (with $\mathrm{U}(0)=0$ ) which is an increasing concave function of profit; thus $U^{\prime}(\cdot)>0$ and $U^{\prime \prime} \leq 0$ so that the firm can be either risk-neutral or risk-averse. As a simplification, it is assumed that the probability density function $d \Psi(\epsilon)$ is sufficiently concentrated and compact so that we can approximate the expected utility as (see Pratt (1964) and Samuelson (1970)) 


$$
E[U(\pi)]=U\left(\bar{\pi}-\frac{1}{2} R(\bar{\pi}) q_{i}^{2} \sigma^{2}\right)
$$

where $\bar{\pi} \equiv \mathrm{E}[\pi]$ is expected profit, $R(\bar{\pi})=-\mathrm{U}^{\prime \prime}(\bar{\pi}) / \mathrm{U}^{\prime}(\bar{\pi})$ is the Arrow-Pratt measure of absolute risk aversion, $\sigma^{2}$ is the variance of price, and $\frac{1}{2} R(\bar{\pi}) q_{i}^{2} \sigma^{2}$. is interpreted as the risk premium.

Furthermore, without any further restrictions on the random demand function (1), the variance of $\mathrm{p}$ is not a constant but is in general some function of q. We can therefore generally write

$$
\sigma^{2} \equiv \sigma^{2}\left(q, s^{2}\right) \text { with } \frac{\partial \sigma^{2}}{\partial s^{2}}>0
$$

where $s^{2}$ is the variance of the random variable $\epsilon$. The specification of the stochastic demand function given by (1) and (4) is completely general and innocuous. No further restrictions are required regarding the sign of $\partial \sigma^{2} / \partial q--t h u s$ nearly all classes of stochastic demand functions are admissible. 5

With the above assumptions, we shall now characterize the properties of competitive equilibrium. Firstly, equilibrium with entry requires each firm to obtain only zero expected utility. Given $U(0)=0$, and using (3), this condition reduces to

$$
\Delta^{0} \equiv \bar{\pi}-\frac{1}{2} R(\bar{\pi}) q_{i}^{2} \sigma^{2}=0 \quad \forall i
$$

which simply states that the expected profit of each firm must cover its risk premium.

Furthermore, in equilibrium, each firm's output level $q_{i}$ is optimally chosen to maximize expected utility (3). This yields, after using (5) and some manipulations, the first-order conditions

$$
\Delta=\bar{p}-\left\{c^{\prime}\left(q_{i}\right)+R(\bar{\pi}) q_{i} \sigma^{2} /(1+\eta(\bar{\pi}))\right\}=0 \quad \forall i
$$


Optimality therefore requires firms to equate expected price $\bar{p} \equiv E[p]$ with its 'fuIl' marginal costs, composed of its marginal production cost $C^{\prime}\left(q_{i}\right)$ and its marginal risk avoidance (or cost of uncertainty) $\mathrm{Rq}_{i} \sigma^{2} /(1+\eta)$. The term

$$
\eta(\bar{\pi}) \equiv-\frac{\mathrm{R}^{\prime}(\bar{\pi}) \cdot \bar{\pi}}{\mathrm{R}(\bar{\pi})} \text {, with } 1>\eta(\bar{\pi})>0 \text {, }
$$

is defined as the elasticity of absolute risk aversion. The restrictions, $1>\eta>0$, is a direct consequence of Arrow's (1974) propositions that the most plausible restrictions on the utility function should be such that absolute risk aversion be decreasing (which implies $\eta>0$ ) and relative risk aversion be increasing (which implies $1>\eta$ ). It is important to add that if the firm is risk neutral $(R=0)$, then the second-order condition requires the firm's marginal production cost be increasing (i.e. $c^{\prime \prime}\left(q_{i}\right)>0$ ). With risk aversion, however, the second-order condition

$$
\Delta_{\mathrm{q}_{i}}<0
$$

does not preclude the possibility that optimality condition (6) can be satisfied even with decreasing marginal production cost (i.e., $c^{\prime \prime}<0$ ). Thus as long as (8) is satisfied, competitive equilibrium under uncertainty and risk aversion can accommodate firms with increasing returns to scale technologies.

The systems of equations (5) and (6) together determine the competitive equilibrium number of firms, $N$, and the size of each firm, $q_{i}$. The industry equilibrium output is therefore $\mathrm{q}=\mathrm{Nq}_{i}$ and the equilibrium price distribution is $p(q, \epsilon)$. 
It is interesting to notice that equilibrium conditions (5) and (6) imply the firms operate with "excess capacity", provided that they are risk averse. From (5) and (6) we get

$$
c\left(q_{i}\right) / q_{i}-c^{\prime}\left(q_{i}\right)=\frac{1}{2} R q_{i} \sigma^{2}(1-\eta) /(1+\eta)>0
$$

Given the restrictions on $\eta$ and assuming risk aversion, we therefore conclude that optimal output is less than minimum average cost output. Notice however, that unlike in Sheshinski and Dreze (1976), excess capacity in our model does not occur if firms are risk neutral.

III. THE EFFECT OF UNCERTAINTY ON EQUILIBRIUM FIRM SIZE AND NUMBER Defining increasing uncertainty as an increase in $s^{2}$ (variance of $\varepsilon$ ), its effects on the equilibrium firm size and number of firms are readily derived by totally differentiating (5) and (6) with respect to $s^{2}$. This yields

$$
\left[\begin{array}{cc}
\Delta_{\mathrm{q}_{i}} & \mathrm{~s}_{\mathrm{N}} \\
\Delta_{\mathrm{q}_{i}}^{0}=0^{6} & \mathrm{~s}_{\mathrm{N}}^{0}
\end{array}\right]\left[\begin{array}{l}
\frac{\partial \mathrm{q}_{i}}{\partial \mathrm{s}^{2}} \\
\frac{\partial \mathrm{N}}{\partial \mathrm{s}^{2}}
\end{array}\right]=\left[\begin{array}{ll}
\frac{\mathrm{Rq}}{1+\eta} & \frac{\partial \sigma^{2}}{\partial s^{2}} \\
\frac{1}{2} \mathrm{Rq}_{\mathrm{i}}^{2} & \frac{\partial \sigma^{2}}{\partial s^{2}}
\end{array}\right]
$$

The solution to (9) gives us the effects on $q_{i}$ and $N$ of an expected-utilitypreserving increase in uncertainty since expected utility is always fixed at its equilibrium value of zero.

In evaluating (9), note that the stability of the equilibrium system requires

$$
\left(\Delta_{q_{i}}+\Delta_{N}^{0}\right)<0
$$

and

$$
-\left(\Delta_{q_{i}}+4_{N}^{0}\right) \Delta *>0
$$


where

$$
\Delta^{*} \equiv \Delta_{q_{i}} \mathrm{~S}_{\mathrm{N}}^{0}
$$

is the determinant of the L.H.S. matrix of (9). It follows, therefore, from (10) and (11) that

$$
\Delta * \equiv \Delta_{\mathrm{q}_{i}} \stackrel{\mathrm{N}}{\mathrm{N}}^{*}>0
$$

which in turn implies

$$
\mathrm{S}_{\mathrm{N}}^{0}<0 \text { since } \Delta_{\mathrm{q}_{\mathrm{i}}}^{\mathrm{O}}<0
$$

by the second-order condition (8). Condition (13) simply says that for there to be a unique number of firms for which expected utility is zero, it is necessary that expected utility be a decreasing function of $\mathrm{N}$. In other words, whenever expected utility is positive (negative), firms will enter (exit) until expected utility is driven to its equilibrium value of zero.

The effects of increasing demand uncertainty on the equilibrium number of firms and firm size will now be shown. Firstly, regarding the effect on the equilibrium number of firms, it follows from (9) that

$$
\frac{\partial \mathrm{N}}{\partial \mathrm{s}^{2}}=\frac{\Delta_{\mathrm{q}}}{2 \Delta^{*}} \mathrm{Rq}_{i}^{2} \frac{\partial \sigma^{2}}{\partial \mathrm{s}^{2}} \leq 0 \text { as } \mathrm{R} \geq 0 \text {. }
$$

The above inequality follows from (4), (8) and (12). Thus increasing uncertainty will reduce the equilibrium number of firms if firms are risk averse; otherwise, if firms are risk neutral, the equilibrium number of firms is unaffected.

In this model where there is no ex post flexibility, firms are committed to production before market price is revealed. Hence profit $\pi=p q_{i}-c\left(q_{i}\right)$ is linear in price p. Consequently, if firms are risk neutral, equilibrium expected profit is unaffected by a mean-preserving increase in price uncertainty 
with the result that no entry or exit of firms will be induced. If firms are risk-averse, however, utility is a strictly concave function of profit and hence of prices. In this case a mean-preserving increase in price uncertainty depresses the equilibrium level of expected utility; thus inducing exit of existing firms.

Our result is in sharp contrast to that of Sheshinski and Dreze (1976), and Lippman and McCall (1981) who show that the equilibrium number of riskneutral firms will increase with increasing demand uncertainty. In their world of complete ex post flexibility where firms need not commit themselves to production ex ante but can instead produce instantaneously at ex post price equal to marginal cost, price instability becomes a desirable effect. This is because ex post flexibility implies that profit is now a convex function ${ }^{7}$ of prices so that a mean-preserving increase in price fluctuation will raise the equilibrium expected profit which consequently attracts the entry of new firms. Introducing risk aversion into their model will obviously produce an ambiguous result, i.e., equilibrium number of firms may expand or contract. The logic is straightforward. Risk aversion implies that utility is a concave function of profit, but ex post flexibility implies profit is a convex function of price. Thus utility may be a concave or convex function of prices depending on the size of the two counteracting effects. If the former (latter) is true, then increasing demand uncertainty will decrease (increase) the equilibrium number of firms.

Turning now to the effect of increasing demand uncertainty on the equilibrium firm size, (9) again implies (after using (2), (4), (5) and (7)) 


$$
\begin{aligned}
\frac{\partial q_{i}}{\partial s^{2}} & =\frac{R q_{i} \partial \sigma^{2} / \partial s^{2}}{2(1+\eta) \Delta^{*}}\left[2 \Delta_{N}^{0}-q_{i}(1+\eta) \Delta_{N}\right] \\
& =B\left[(1-\eta)-\frac{2 \bar{\pi}}{(1+\eta)} \frac{\partial \eta}{\partial \bar{\pi}_{i}}\right] \\
& (-) \quad(+) \quad(?)
\end{aligned}
$$

where $B \equiv\left\{\frac{\bar{\pi} \partial \sigma^{2} / \partial s^{2}}{\sigma^{2}(1+\eta) \Delta *}\right\} \cdot \frac{\partial \bar{p}}{\partial q}<0$. The effect of increasing demand uncertainty on the equilibrium firm size is less straightforward. Various special cases, however, will be considered.

In the case of risk-neutral firms $(R=0)$; it is obvious from (15) that

$$
\frac{\partial q_{i}}{\partial s^{2}}=0 \quad \text { since } R=0
$$

If, however, firms are risk averse $(R>0)$, then provided the elasticity of absolute risk aversion is constant $(\eta=$ constant), it follows from (15) that

$$
\frac{\partial \mathrm{q}_{i}}{\partial \mathrm{s}^{2}}<0 \text { if } \mathrm{R}>0 \text { and } \eta=\text { constant }
$$

In this case increasing demand uncertainty reduces the equilibrium firm size.

It is worth adding that

$$
\frac{\partial \eta}{\partial \bar{\pi}}=\frac{\eta}{\pi}\left[\frac{R^{\prime \prime} \bar{\pi}}{R}+1+\eta\right]
$$

so that the assumption that $\eta=$ constant implies $\mathrm{R}^{\prime \prime}>0$. The term $\mathrm{R}^{\prime \prime}$, however, involves also the fourth-order derivatives of the utility function on which neither economic theory nor intuition has much to say regarding its further restrictions. Thus it is equally plausible that $R^{\prime \prime} \leq 0$ which, from (18), implies $\partial \eta / \partial \bar{\pi}>0$ (i.e., $\eta$ is no more a constant). To consider these cases, substituting (18) into (15), yields 


$$
\frac{\partial \mathbf{q}_{i}}{\partial s^{2}}=B\left[(1-\eta)-\frac{2 \eta}{(1+\eta)}\left\{\frac{R^{\prime \prime} \bar{T}}{R}+1+\eta\right\}\right]
$$

In the case where $R^{\prime \prime}=0$, it follows that

$$
\frac{\partial \mathrm{q}_{\mathrm{i}}}{\partial \mathrm{s}^{2}}=\mathrm{B}(1-3 \eta) \gtrless 0 \text { as } \eta \gtrless \frac{1}{3} \text { if } \mathrm{R}^{\prime \prime}=0 \text {. }
$$

Thus we cannot rule out the possibility (whenever $\eta>\frac{1}{3}$ ) that equilibrium firm size may even increase in response to increasing demand uncertainty. This is indeed surprising in the face of risk-aversion assumption. For the case where $R^{\prime \prime}<0$, $\eta$ must exceed a number smaller than $\frac{1}{3}$ in order to produce the firmexpansion result.

Finally, it should be noted that the effects of increased uncertainty on excess capacity are immediately determined from its effects on the firm size. Thus, in general we cannot predict the effects of an increase in uncertainty on the firms' excess capacity.

\section{CONCLUSION}

Firms facing a stochastic demand environment can in general choose their optimal mix of ex ante production and (a more costly) ex post production strategies. On one extreme where there is no cost differences between the two strategies, it is obvious that only the ex post production strategy will be pursued. In this case, firms simply await the revelation of the market price and instantaneously produce at price equal to marginal cost. Unfortunately, such complete ex post flexibility is an unattainable luxury for most industries because this strategy (which requires the use of a higher-speed production technique or which uses overtime work) inadvertantly incurs a higher cost compared to the ex ante production strategy. It is even more surprising that 
the few existing studies (e.g., Dreze and Gabszewicz (1967), Sheshinski and Dreze (1976), and Lippman and McCal1 (1981))--aimed at describing the effects of uncertainty on industry equilibrium--were confined to a model that has limited empirical content.

In this paper, we consider the situation where firms cannot afford the more-expensive ex post flexibility strategy and must instead contend with ex ante production before the ex post market price is revealed. Although this behavior represents the other polar case of ex post non-flexibility, it nonetheless, has greater empirical content: Production processes that involve long time lags (e.g., agricultural productions) are usually operated under this behavioral mode. The effects of uncertainty on the industry equilibrium structure obviously differ between the two polar modes of behavior and their contrasting predictions are summarized below.

In the complete ex post flexibility model, the existing results (which are confined to risk-neutral firms only) predict that firms in long-run equilibrium will operate with excess capacity and, furthermore, increasing demand uncertainty will increase the equilibrium number of firms. Introducing risk aversion should not affect the excess capacity result but it is shown in this paper that, with risk aversion, the prediction regarding the equilibrium number of firms becomes ambiguous: increasing uncertainty will tend to reduce (increase) the equilibrium number of firms if risk aversion is large (small).

As a contrast, in our model of ex $\underline{\text { post }}$ non-flexibility, risk-neutral firms in long-run equilibrium will not operate at excess capacity (but at minimum average cost); and increasing demand uncertainty will not affect 
the equilibrium number and the size of risk-neutral firms. With risk-aversion, however, firms in equilibrium will operate at excess capacity; furthermore, increasing demand uncertainty will reduce the equilibrium number of firms but its impact on the equilibrium size of each firm is ambiguous. 


\section{REFERENCES}

K. J. Arrow, Essays in the Theory of Risk Bearing, North-Holland, 1974.

J. H. Dreze and J. J. Gabszewicz, "Demand Fluctuations, Capacity Utilization and Prices," Operations Res. Verfahren, 1967, 3, 119-41.

E. F. Fama, "Agency Problems in the Theory of the Firm," Journal of Political Economy, April 1980, 88, 288-308.

J. Hey, Uncertainty in Microeconomic Theory, New York University Press, 1979.

H. Leland, "Theory of the Firm Facing Random Demand, American Economic Review, June 1972 , 62, 278-91.

C. Lim, "Ranking of Behavioral Modes of the Firm Facing Uncertain Demand," American Economic Review, March 1980, 70, 217-24.

S. A. Lippman and J. McCaIl, "Competitive Production and Increases in Risk," American Economic Review, March 1981, 71, 207-11.

W. Y. Oi, "The Desirability of Price Instability Under Perfect Competition," Econometrica, Jan. $1961, \underline{29}, 58-64$.

J. W. Pratt, "Risk Aversion in the Small and in the Large," Econometrica, 1964, 32, $122-36$.

P. A. Samuelson, "The Fundamental Approximation Theory of Portfolio Analysis in Terms of Means, Variances, and Higher Moments," Review of Economic Studies, Oct. 1970, 37, 537-42.

E. Sheshinski and J.H. Dreze, "Demand Fluctuations, Capacity Utilization, and Costs," American Economic Review, Dec. 1976, 66, 731-42.

S. Turnovsky, "Production Flexibility and Uncertainty," International Economic Review, June 1973, 395-413. 


\section{FOOTNOTES}

${ }^{1}$ See Hey (1979) for a survey of the literature.

${ }^{2}$ Paper in preparation.

${ }^{3}$ See Fama (1980) for an excellent discussion on the question of why separation of security ownership from managerial control can be an efficient form of economic organization.

${ }^{4}$ For convenience (since all firms are the same) we drop the firm subscript and write $\pi=\pi_{i}$ for all $i$.

${ }^{5}$ For the class random demand functions in which the random variable enters additively, for example $p(q, \epsilon)=p(q)+\phi(\epsilon)$ (with $\left.p^{\prime}(q)<0, \phi^{\prime}(\varepsilon)>0\right)$, then $\partial \sigma^{2} / \partial q=0$. For the class of functions where the random variable enters in a multiplicative manner, for example $p(q, \epsilon)=p(q) \phi(\epsilon)$, then $\partial \sigma^{2} / \partial q<0$. Examples of demand functions for which $\partial \sigma^{2} / q>0$ are $q(p, \epsilon)=q(p) \phi(\epsilon)$ where $\mathrm{q}$ is quantity demand with $\mathrm{q}^{\prime}(\mathrm{p})<0$ and $\sigma^{2}$ is, as before, the price variance. Our results in this paper are invariant and are generally applicable to all these forms of demand functions.

${ }^{6}$ From the definition of $\Delta^{\circ}$ in (j), note that $\dot{\Delta}_{q_{i}}^{n}=\dot{\Delta}-\dot{0}$ as in (6).

${ }^{7}$ If firms are allowed to produce at ex post price equal to marginal cost: $p=c^{\prime}\left(q_{i}\right)$, then we can write output response to price as $q_{i}=h_{i}$ (p) where $h_{i}^{\prime}=1 / C^{\prime \prime}>0$ since $c^{\prime \prime}>0$ by the second-order condition for optimum . Profit now becomes $\pi(p)=p_{i}(p)-c\left(h_{i}(p)\right)$, with $\pi^{\prime}(p)=h_{i}(p)>0$ and $r^{\prime \prime}(p)=h_{i}^{\prime}(p)>0$. Thus profit is a strictly convex functin of $! \cdot$ 